\title{
Laser Beam Melting for Tooling Applications - New Perspectives for Resource-Efficient Metal Forming and Die Casting Processes
}

\author{
Bernhard Müller ${ }^{1}$, Ralf Hund ${ }^{2}$, Roland Malek ${ }^{3}$, and Nancy Gerth ${ }^{4}$ \\ ${ }^{1}$ Fraunhofer Institute for Machine Tools and Forming Technology IWU, Chemnitz, Germany \\ ${ }^{2}$ BRAUN CarTec GmbH, Schwalbach, Germany \\ ${ }^{3}$ Volkswagen AG, Wolfsburg, Germany \\ ${ }^{4}$ Druckguss Heidenau GmbH, Dohna, Germany
}

\begin{abstract}
Applying additive manufacturing technologies in the tooling sector is reaching a new level with Laser Beam Melting, since this technology allows layer-by-layer manufacturing of completely dense tool and die inserts in standard high-alloyed tool steel. The technology is now ready to go beyond applications in low impact processes like plastic injection moulding and enters metal working process applications like metal forming and die casting. The potential of additive manufacturing for added value in tooling applications has now been investigated for various metal working processes.

The paper presents results of research and pilot application projects to apply laser beam melting to manufacture tooling for metal forming and aluminium die casting. The paper describes the shortcomings of conventional cooling channels in metal working tools and the resulting inadequate cooling effect in critical areas. The paper shows how innovative cooling systems can be implemented in metal working dies through laser beam melted die inserts. Cooling of specific die areas has been realized by placing specially designed cooling channels very close to the die cavity, targeting shorter cycle times, structural and dimensional quality improvements of manufactured metal parts and a reduction of energy consumption for cooling and idle times of forming presses and die casting machines. The paper will present the achieved results for both metal working applications and point out the general potential of additive manufacturing in tooling.
\end{abstract}

Keywords: Additive Manufacturing, Laser Beam Melting, Selective Laser Melting, tooling, metal forming, die forging, press hardening, die casting, conformal cooling, resource-efficiency.

\section{$1 \quad$ Introduction}

Metal forming and casting are important production technologies in Europe and worldwide. Virtually any product on the market contains formed metal parts or cast components, especially in the automotive sector. A serious challenge that manufacturers are facing today is that clients expect ever-rising complexity and functional 
integration in all products, pushing business to providing global solutions and the conventional manufacturing technologies to their limits. From a technological point of view, main problems the industry is facing are reproducibility of the production process conditions, part quality and cycle time. This asks for new knowledge of material behaviour and results in a lot of extra effort to continuously adjust processing parameters.

The emerging additive manufacturing technology laser beam melting has been identified to have the potential to realize tooling features out of standard tool steels due to its virtually unlimited freedom of design that can fulfil the desired functions in metal forming tools and casting moulds. The additive approach in building up tooling components layer by layer is the key factor to provide this freedom of design without compromises for manufacturability, cost for complexity and tool-modularity.

\section{State of the Art}

\subsection{Press Hardening}

To implement lightweight, high-strength steel parts in car bodies, the press hardening (hot sheet metal forming) technology is an emerging technology. The sheet metal is heated above the austenitization temperature (more than $800{ }^{\circ} \mathrm{C}$ ) and rapidly cooled down during the forming process below $200{ }^{\circ} \mathrm{C}$, whereby a martensitic microstructure is created [1]. This process is especially advantageous when different demands are placed on one component, for example a component that needs to have one area of higher strength or hardness and another area with higher elongation [2]. The cycle time in press hardening is determined to as much as $30 \%$ (see Figure 1) by the cooling time (holding time of closed die after forming operation before re-opening for part extraction).

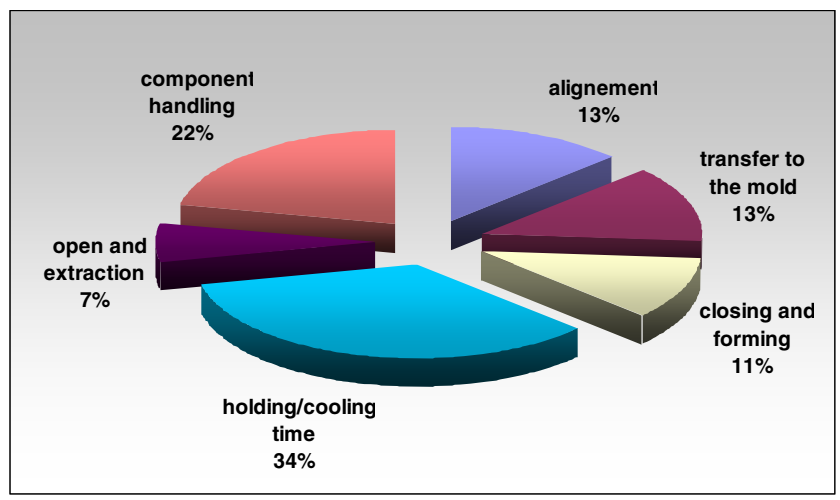

Fig. 1. Exemplary illustration of the cycle time in press hardening 
So it was assumed that, through an optimized cooling system manufactured by laser beam melting, cycle time of the hot forming process can be reduced significantly. Furthermore, it was assumed that, by increasing the cooling rate, an improvement of the component's strength can be achieved. Subsequently, through the improved mechanical properties, a further reduction of wall thickness is getting possible. That results in a reduced need of raw material and lesser component weight and therefore in resource savings in manufacturing and use of the component. Due to the reduced cycle time, reduced energy demands and potential material savings, savings in resource consumption of up to 10 per cent per produced part were expected to be possible.

The setup of a hot forming tool (see Figure 2) is more complex than that of a conventional one. Mainly this is due to the fact that cooling channels must be implemented into punch and die. The implementation of the channels is usually done by deep drilling or a segmentation of the tool. Due to complex geometry of the tools, the cooling system design is especially demanding for tool manufacturers. The added complexity of cooling bores increases the expenses for hot forming tools. Current production effort is estimated with about one hour per meter borehole and a high consumption of resources (energy, drilling oil, compressed air, etc.). The mostly angled cooling bores also require additional preparation like mirroring and/or generation of a pilot hole. Therefore, the effort of work preparation like creating CAM tool paths and drilling programs as well as defining the workflow (e.g. re-clamping) is significant.

\subsection{Aluminium Die Casting}

High performance aluminium casting components need high performance quality. This applies especially to innovative engine concepts which offer substantial improvement in performance and efficiency and leads to high thermo-mechanical loads, especially on lightweight powertrain components. As a result, the die casting industry is constantly faced with new challenges. In practice, the manufacturing of complicated components often proves very difficult as series of casting errors such as cold shots, die marks, mends, embeddings, sink marks or heat checking can lower the quality. At this point, the issue of porosity (either shrinkage or gas porosity) plays a key role. Shrinkage porosity is also known as solidification porosity and blowholes. It is the result of the casting material's thermo-physical properties which occur during solidification and appears as volume deficits. Gas porosity can appear in the form of gas inclusions due to fluid mechanical reasons or as gas precipitation during solidification due to thermo-dynamical reasons [3].

Up to now, a selective temperature control of individual areas close to the die cavity could only be realized with enormous effort and limitations. Hence, the result: an insufficient attainability of the target temperature and often inadequate heat dissipation in the critical areas. 


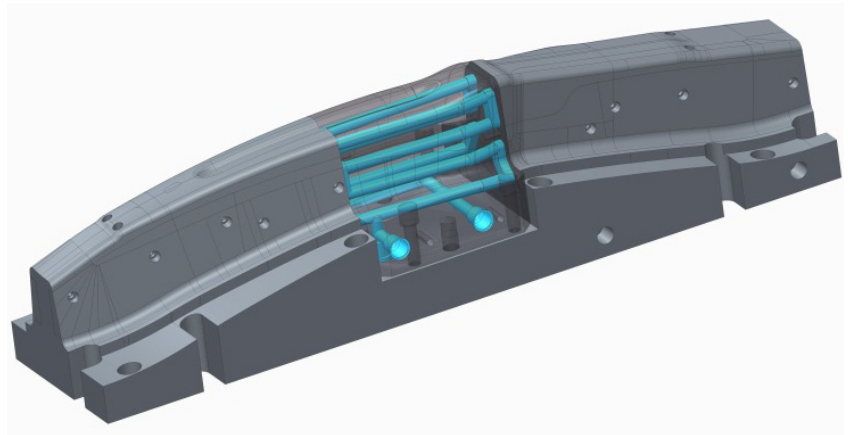

Fig. 2. Tool for hot sheet metal forming

\subsection{Laser Beam Melting}

A way to reduce the manufacturing effort while increasing the freedom in cooling system design is the application of additive manufacturing in tool and mould making. So called rapid tooling applications emerged very soon after introduction of first layer-based rapid prototyping technologies like stereo lithography or laminated object manufacturing (LOM). Since no metallic or other durable material could be directly processed in an additive manufacturing process at that time, the need for metallic or series-material prototypes lead to first applications of layer manufactured parts as tooling like sand and investment casting patterns [4], as well as prototype and preseries moulds for various moulding processes [5]. Direct rapid tooling was limited to very low volume production, for higher volumes only indirect processes like Keltool were applicable [6]. First research was also done toward metal forming operations with layer-manufactured tooling [7].

With further development of the selective laser sintering process (SLS) towards direct metal laser sintering (DMLS), it became possible to directly layer manufacture metallic tooling. Limitations of that technology were initially to be found in the necessary second process step of finish sintering with significant shrinkage ratios or otherwise the infiltration with a low melting bronze alloy. This infiltrated material was able to survive complete pre-series or low-series production up to a couple of thousand shots in plastics processing like injection moulding [8]. Material properties were still far away from those of standard tooling materials like hot-work steel.

This was changed with the emergence of laser beam melting technologies. Standard tooling materials like 1.2709 can now be processed and completely melted rather than only superficially fused to an almost 100 per cent dense microstructure. Now it has become possible to use laser beam melting technologies to manufacture full series tooling for mass production without tool life limitations compared to conventional tool making by machining or EDM.

Additive manufacturing allows overcoming the limitations of today's common manufacturing technology and opens up new ways for cooling of metal forming tools, e.g. in die forging [9]. Components and tools can be manufactured directly based on 3D CAD data from powdered materials such as hot work steel and built up layer-wise. 
For the additive manufacturing process of laser beam melting, metal powder is the starting material from which a defined contoured layer is formed. The powder is selectively melted layer by layer by a laser and solidifies after cooling into a solid body (see Figure 3). Therefore, the component is produced by adding layers of material and not by removing. Thanks to laser beam melting, conformal cooling is already state of the art in mould making when it comes to injection moulding. But in metal forming and die casting, tool load in terms of temperature, compression and tension is considerably higher and more demanding, setting a new challenge for laser beam melted tooling.

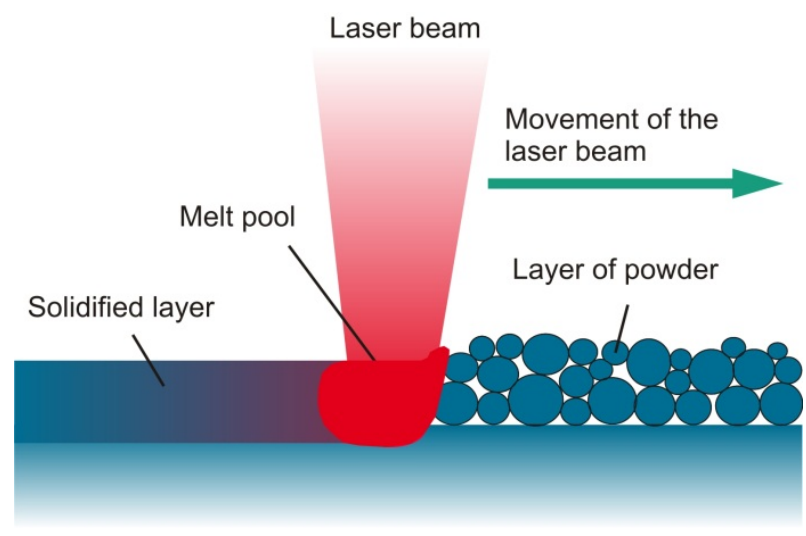

Fig. 3. Laser beam melting principle

\section{The Projects}

\subsection{Press Hardening}

Within the so-called Innovation Alliance "Green Carbody Technologies", funded by the German Federal Ministry of Education and Research and combining 60 companies and research institutes in joint research to increase resource efficiency along the entire car body production chain, it has been investigated how the hot sheet metal forming process of press hardening can become more resource efficient by using innovative laser beam melted tooling inserts. Thereby, specific die areas were getting locally tempered by arranging cooling channels very close and conformal to the cavity shape. Research aims were: the reduction of process cycle time, further enhancement of mechanical properties of hot formed metal sheets, further reduction of wall thickness and a general reduction of amount of energy used per component in its manufacturing.

The aim of the presented Innovation Alliance project was to develop and manufacture tool inserts with a new type of cooling system to improve resource efficiency in hot sheet metal forming. Therefore, thermo-fluidic simulation and laser beam melting were used. 
After investigating current mass production, the project partners have jointly developed a representative demonstrator (see Figure 4). To enable easy transfer of the project's results into mass production, the demonstrator's geometry is very similar to a serial component. The design reflects a typical hot forming component and its difficulties and potential problems. It incorporates geometric features such as curved surfaces and cavities to demonstrate limitations of conventional, deep hole drilled cooling channels in terms of rapid and homogeneous cooling of the sheet metal component.

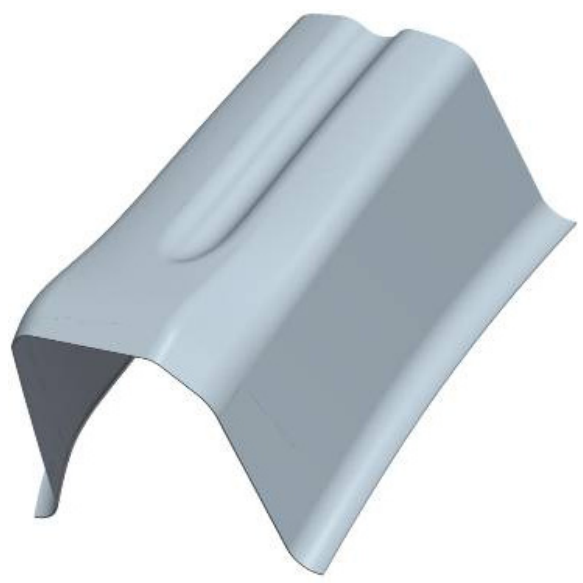

Fig. 4. Demonstrator

The tool design and the cooling system design were done based on conventional manufacturing methods such as milling and deep drilling. Parallel to this, the development of the innovative, conformal cooling system began. Various iterations of the cooling system were designed. First proof of positive effects of the optimized tool temperature control was provided by numerical simulation (see Figure 5).
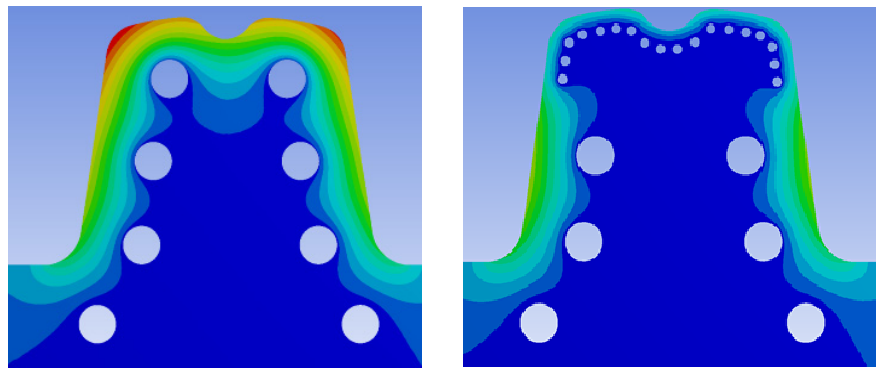

Fig. 5. Thermal simulation: comparison of conventional drilled cooling channels (maximum temperature in the tool $191{ }^{\circ} \mathrm{C}$, left) and optimized cooling channels with a significantly lower thermal load $\left(81^{\circ} \mathrm{C}\right.$, right $)$ 
In the project, thermal behaviour of the tool as well as coolant flow was analysed and different cooling geometries were compared. The input variables such as compression force, work piece temperature, coolant temperature, flow rate, pump power and surface roughness of cooling channels were adopted from the mass production system. In order to assure comparability of simulation results with reality, thermal conductivity of specific materials in use were determined experimentally on the basis of material samples. The optimum cooling channel geometry was designed based on simulation results, considering technical characteristics of the laser beam melting technology (see Figure 6).

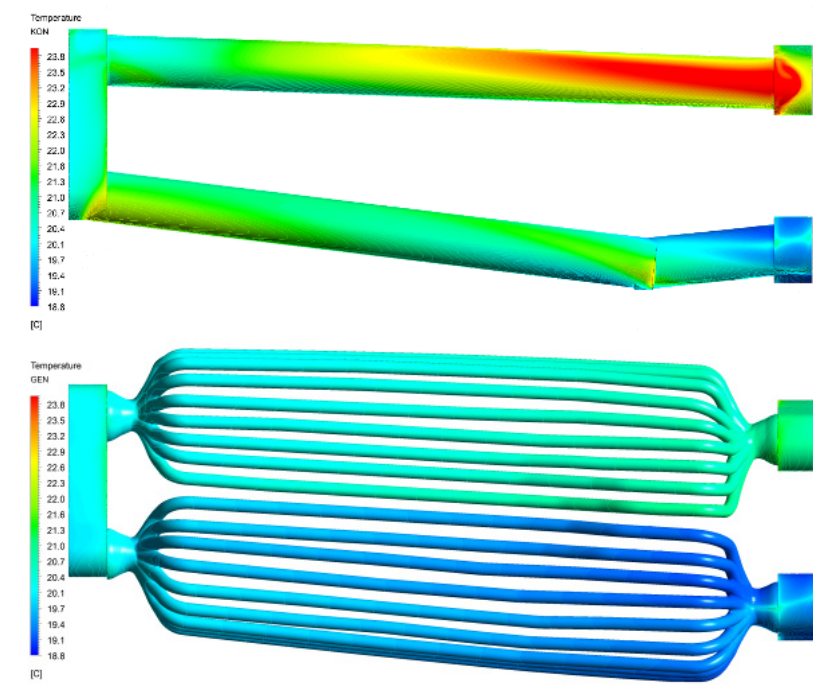

Fig. 6. Comparison of the temperature gradient in conventional cooling system (top) and in new cooling system (bottom)

Temperature distribution in the component (see Figure 7), according to thermofluidic simulation, showed inhomogeneous cooling due to the conventional die and limitations in its manufacturing when it comes to getting the cooling channels very close and conformal to the surface. Due to simulation, the cooling system's efficiency could be constantly improved and resulted in a homogeneous temperature distribution within the sheet metal component (see Figure 7). Thanks to the optimized cooling it is possible to cool down the parts more evenly and more rapidly. The simulation suggested the holding time to be shortened by 45 per cent from initially 11 down to 6 seconds, using the same temperature profile like in conventional cooling.

The most critical area was localized in the die's deepest cavity, where - due to limitations of conventional drilling - standard cooling channels have the longest distance to the cavity surface. Therefore, a complete re-design of the die's entire cooling 

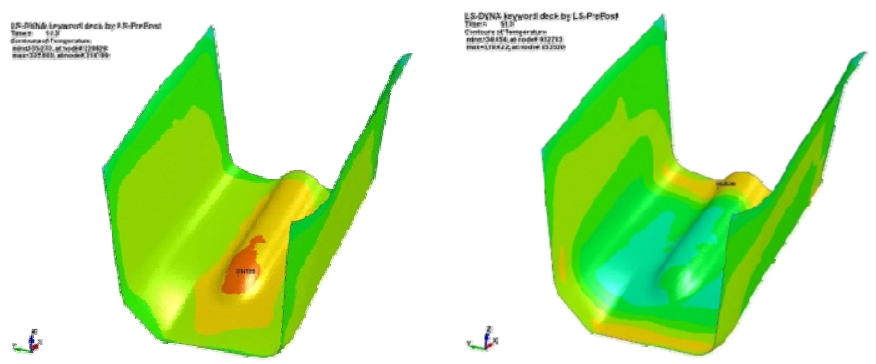

Fig. 7. Comparison of the temperature distribution in the sheet metal component with conventional cooling system (component temperature in the critical area $335{ }^{\circ} \mathrm{C}$, left) and with the optimized cooling system $\left(177^{\circ} \mathrm{C}\right.$, right $)$

system was not even necessary. The base body was left untouched and so the redesign focused only on the critical areas around the deep cavity. Because of that and in order to achieve the best synthesis of greatest value, short production time and low costs it was decided to manufacture the tooling insert by so-called hybrid tooling, a combination of conventional manufacturing technologies like milling, drilling, turning with additive manufacturing like laser beam melting.

In this case, the laser beam melted functional structure with optimized cooling channels was applied on a conventionally milled base body (see Figure 8). Only rough machining and heat treatment needed to be done on the base body to prepare it for laser beam melting of the top section. To get the best possible bonding between base body and functional structure with conformal cooling system, the upper base body surface was grinded and afterwards sand blasted. The base body was then placed and fixated in the laser beam melting machine. After the functional structure was applied by laser beam melting, the tool insert (see Figure 8) was removed from the machine and heat treated for hardening and stress relief within the laser beam melted section.
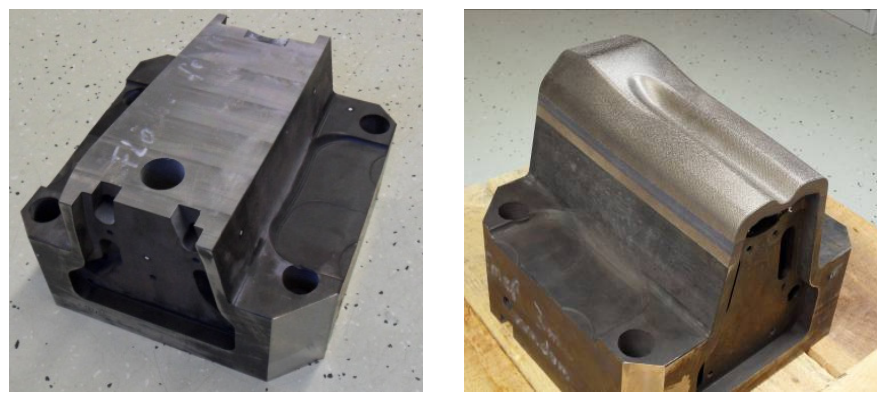

Fig. 8. Tool insert - milled base body (left) and ready for finish-machining (right)

To confirm simulation results, extensive forming trials were done. The trials took place on a standard hot forming press, under production-like conditions and applying a variety of different parameter settings. With the help of latest equipment like thermo-camera, temperature sensors and computer-assisted analysis, all relevant data from the trials were recorded and afterwards analysed. 
In a first test series, the temperature curve of the cooling process, starting from an initial temperature of $200{ }^{\circ} \mathrm{C}$, was recorded by thermal sensors and a thermo-imaging camera. In this case, the additive manufactured tool with the new cooling system cooled down six times faster than the conventional tool with drilled cooling channels (see Figure 9). In further experiments, different holding/cooling times were run with varying cooling water flow. For temperature recording, once again thermocouples were used in the tool and thermographic imaging for the formed component. The results show that, using the new type of additively manufactured tool inserts, the holding (cooling) time could be reduced by 50 per cent, which corresponds in this particular case to a total cycle time reduction of 20 per cent.
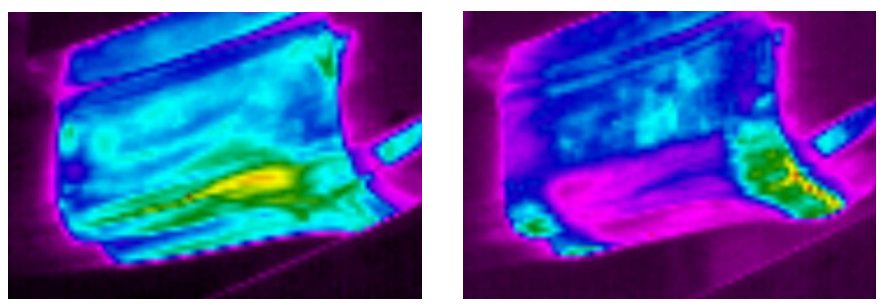

Fig. 9. Thermal image of the die after 5 seconds of cooling with the conventional cooling system (temperature in the top section of the tool $142{ }^{\circ} \mathrm{C}$, left) and with the additively manufactured cooling system $\left(68^{\circ} \mathrm{C}\right.$, right $)$

\subsection{Aluminium Die Casting}

The newly developed V8-TFSI engine of Audi combines efficiency and high performance. The Biturbo presents its Premium character with a torque of up to $650 \mathrm{Nm}$ in a range of 1.700 up to $5.5001 / \mathrm{min}$ and power outputs of up to $382 \mathrm{~kW}$ (520PS). The engine consists of a $90^{\circ} \mathrm{V}$-cylinder block and the beneath attached bedplate [10]. The component is manufactured by die casting in the alloy EN AC-Al Si9Cu3 (Fe) and is equipped with moulded crankshaft bearing caps made of spheroidal graphite iron to optimize strength, acoustics and main bearing (Figure 10).

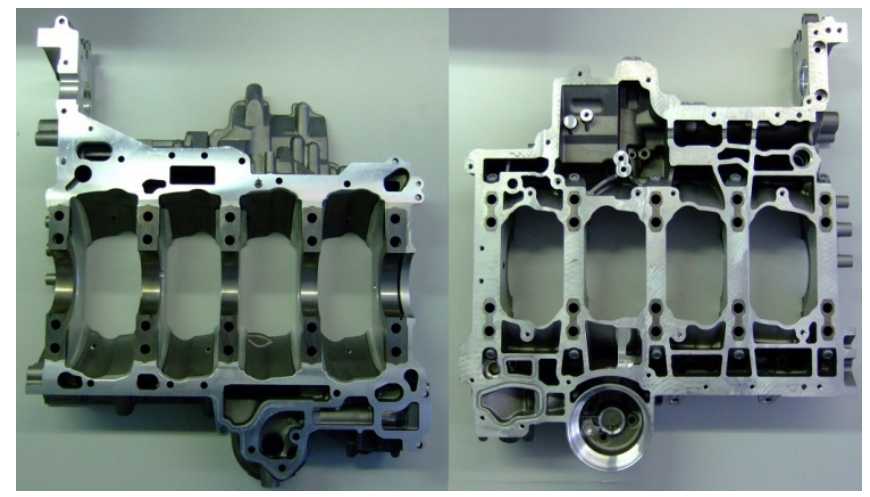

Fig. 10. Audi bedplate V8-TFSI (view of both sides) 
In the development stages, the bedplate has already been classified as a highly complex component. High customer requirements on the die cast component lead to a particularly subtle approach in terms of design and manufacturing of the component with regard to the main criteria die casting technology, die casting alloy and casting die. Therefore, the influencing factors such as material properties, process and technological parameters of the die casting machine, die design under usage of an optimal gating and ventilation system were mutually modified.

The complicated bedplate was on a basic state after first series of manufacturing which has been continually developed and modified since then. The quality control, documentation and evaluation provided the basis for the on-going process analysis as well as for creation and realization of the action plan in order to optimize the component. Defects like local weak spots, shrink marks, cold runs and hot cracking are mostly thermal in nature [10] and have been improved via adaptations of the thermal management and also by precise adjustments of process parameters. Particular difficulties were, due to critical porosities, specifically in the area of the oil filter cartridge. Figure 11 shows the porosity's position in the component and its magnitude.

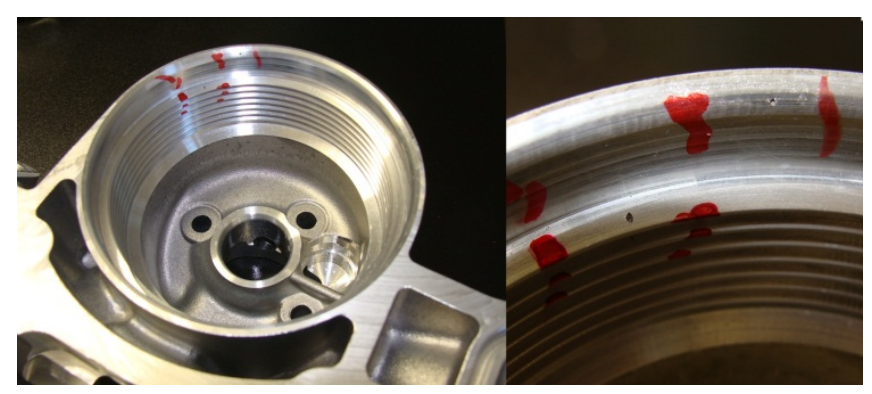

Fig. 11. Porosity in bed plate at oil filter cartridge (right: enlarged view)

The micro porosity could not be specified unambiguously - neither by x-ray methods nor computer tomography (CT) scan imaging of the whole bedplate. Material analysis - electron microscopy (REM) and micro CT [12] - provided insight (Figure 12). The pores were a hybrid of gas and solidification porosity. A minimization of the weak spot was partially attained on the conventional way by melt treatment, optimization of process parameters, optimization of process technology and periphery, optimization of process monitoring and management and optimization of the casting die, in particular the gating and venting system.

The threshold value of pore sizes, especially in the oil filter cartridge zone, should prevent a possible damage of the cartridge incl. sealing ring when it comes to mounting or removing of the filter, a material fatigue or damage of the component and exclude the leakage oil. A geometrical adaptation of the component by the Audi designer was limited by the given installation space and was no option. Therefore, new production technologies had to be applied in order to ensure production output, quality and efficiency of the bedplate. 


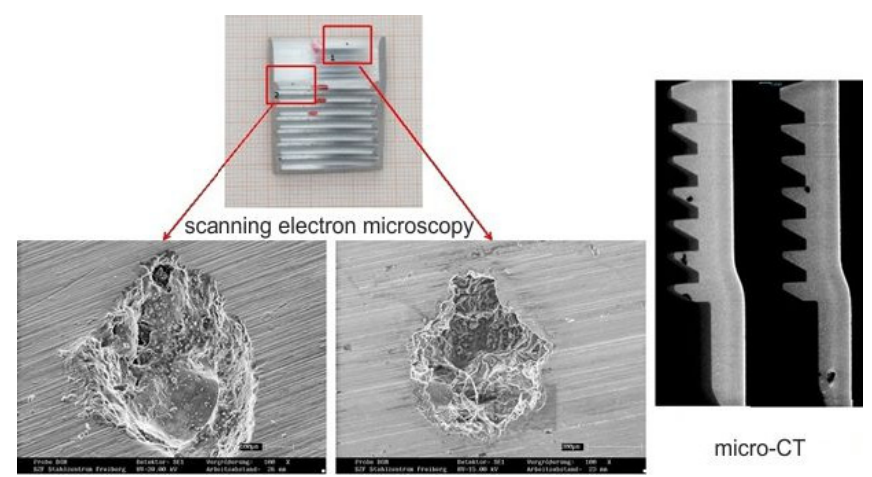

Fig. 12. Material analysis in the field of oil filter pot REM (left), micro-CT (right) (source: TU Freiberg - Foundry Institute)

The idea was to implement an additional conformal cooling system besides the common tempering of the mould which was allowed to consist of only minute cooling channels due to the wall thickness. The conflict was to maintain the energy input (temperature) by the melt to guarantee an even die filling and simultaneously dampening the momentum of the melt at the sprue to ensure a homogenous material solidification. Conformal cooling was implemented by individual laser beam melted tool inserts (Figure 13).

In this case, the tool insert was manufactured in hybrid design to realize a preferably economical production. It represents the combination of a conventional manufactured base body and an additively built-on functional geometry. This allows the best possible synthesis of greatest added value, short production time and lowest cost.

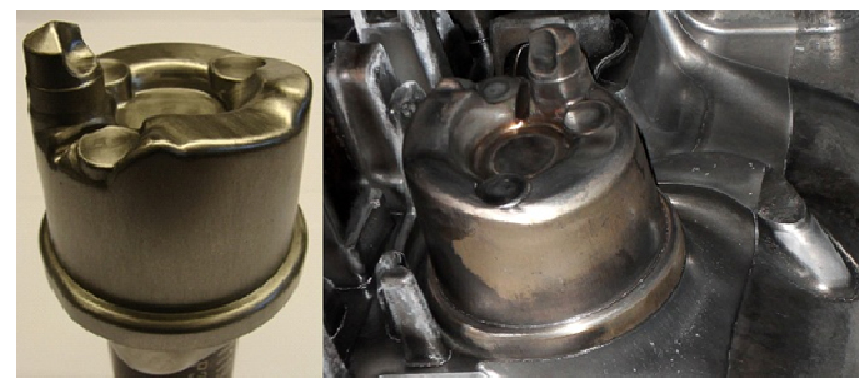

Fig. 13. Laser beam melted tool insert (left) and installed as a component in the die (right)

By using the additive laser beam melting technology, it became possible to focus on functionality and efficiency of the cooling system with no regard to manufacturability. With the help of numerical simulation and with consideration of existing cooling channels and connectors, an application-specific, innovative cooling system was developed. On the one hand, numerical simulation served as a tool to ensure the shortest possible distance of the cooling to the cavity, while still allowing a sufficient strength of the tool insert (FE simulation). On the other hand, simulation allowed a 
step-by-step optimization of the cooling system (thermal simulation) ranging from a simple spiral design to a complex system of small channels (see figure 14). In general, special care has been taken in cooling system design with regard to the total cross section of all individual cooling channels combined, which should correspond to the cross section of the coolant intake and outlet for a homogeneous flow distribution across all channels and therefor the most homogenous temperature distribution possible. Creating such a complex cooling system, including specific channel layout with wide contours and generously rounded transitions, in order to keep pressure losses to a minimum, became possible by using additive manufacturing technology only.

The first additively manufactured, optimised tool insert was run in the casting die of the bedplate and subsequently the follow-up version in series production. Test runs already proved function of tool insert and innovative cooling system. Thereupon, the insert was permanently attached to the die and the cooling channels could be connected to a specially water temperature control unit via conventional hoses. The cooling was gradually adjusted in sensitive tempering phases and a recognizable influence could be recorded. In a range of only 10 Kelvin, the component area showed no critical overheating or hypothermia. This temperature range needed to remain constant throughout the whole casting process. Immediate analyses of different tempering steps at the produced components via x-ray analysis, quick sample processing and additional materials analysis showed that gas and shrinkage porosity was significantly reduced and minimized to a level of permissible porosity.

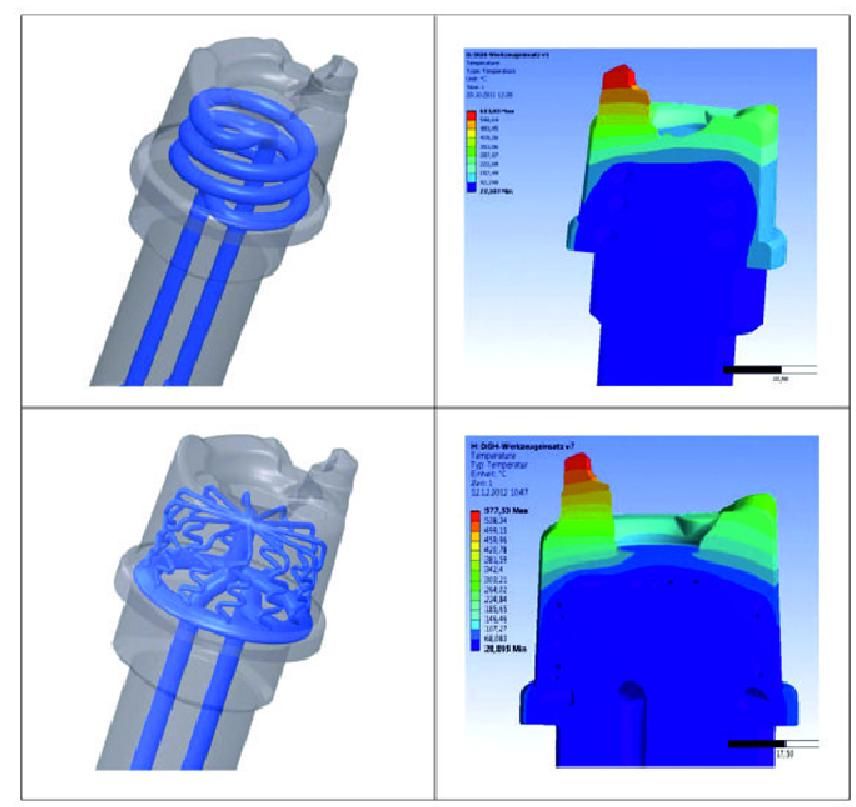

Fig. 14. Laser beam melted tool insert (left) and installed as a component in the die (right) 
Meanwhile, all measures have been applied in series production. The achieved results could be proved and resulted in a scrap rate reduction of $10 \%$ referring to the error pattern of porosity. The innovative, additively manufactured tool insert enabled $5 \%$ less susceptibility of the process and a $3 \%$ cycle time reduction. Sustainability tests throughout the casting die's complete life cycle have not been finalized yet. Nevertheless, the results enabled a more stable production process of the bedplate without any part design changes and therefore assured a high focus on the component's functionality: a compact power unit, overall length limits and a high degree of integration. A rapid launch in series production could be realized [13][14].

\section{Conclusions}

The paper has described how metal forming and casting tool inserts can be manufactures by laser beam melting. A detailed in-sight has been given through case studies of innovative cooling systems, for hot sheet metal forming as well as for aluminium die casting. In the projects presented in this paper, it could be proved that laser beam melting is a well-suited technology for manufacturing highly complex moulds and tools which go beyond the limits of conventional production technologies. The unique laser beam melting technology opens up ways for new design approaches of cooling systems in metal forming tools and casting dies. This paper's main conclusions are to be found in increasing the cooling rate in hot sheet metal forming and in improving the part quality in light metal die casting and pointed out the superiority of laser beam melting to manufacture this type of tools and tool inserts that made these promising results possible. An enormous improvement in temperature distribution within the tool as well as in the components could be achieved for both manufacturing processes. Due to laser beam melting, component quality can be improved, process cycle times can be reduced significantly and therefore it is possible to increase resource efficiency of series production processes as well as to reduce the amount of energy used to manufacture each part.

\section{References}

1. Engel, B.: Hochfeste Stähle. IBU Vortragsreihe. Universität Siegen (2008), http: / / www . uni-siegen. de/fb11/fw/lehrstuhl/publikationen /pdf/ibu_hochfest.pdf

2. Beck, M.: Mehr als erwärmen und umformen. Industrieforum.net (2008), http: / /www. industrieforum. net/de/blechonlinede/oktober 062008 /rubrik/umformen/mehr-als-erwaermen-und-umformen

3. VDG Verein Deutscher Gießereifachleute: VDG-Merkblatt P201 - Volumendefizite von Gussstücken aus Nichteisenmetallen (Mai 2002)

4. Mueller, B., Kochan, D.: Laminated object manufacturing for rapid tooling and patternmaking in foundry industry. Computers in Industry 39/1(4), 47-53 (1999)

5. Chua, C.K., Hong, K.H., Ho, S.L.: Rapid Tooling Technology Part 2 a Case Study Using Arc Spray Metal Tooling. Advanced Manufacturing Technology 15(8), 609-614 (1999) 
6. Jetley, S., Low, D.K.: A Rapid Tooling Technique Using a Low Melting Point Metal Alloy for Plastic Injection Molding. Journal of Industrial Technology 22(3), 2-8 (2006)

7. Voelkner, W.: Untersuchung der Möglichkeit des Einsatzes der Stereolithographie zum Bau von Blechumformwerkzeugen. DFG-Abschlussbericht. Institut für Produktionstechnik der TU Dresden, Dresden (1997)

8. Ferreira, J.C.: Rapid tooling of die DMLS inserts for shoot-squeeze moulding (DISA) system. Journal of Materials Processing Technology 155-156, 1111-1117 (2004)

9. Neugebauer, R., Mueller, B., Wagner, A.: Direct Rapid Tooling for Die Forging - a new challenge for Layer-Based Technologies. In: Bártolo, P.J., et al. (eds.) Innovative Developments in Design and Manufacturing - Advanced Research in Virtual and Rapid Prototyping, pp. 283-288. Taylor \& Francis, Oxford (2010)

10. Königstedt, J., Aßmann, M., Brinkmann, C., Eiser, A., Grob, A., Jablonski, J., Müller, R.: Die neuen 4.01-V8-TFSI-Motoren von Audi - die konsequente Verbindung von Effizienz und Performance. 33. Internationales Wiener Motorensymposium (2012)

11. Nogowizin, B.: Theorie und Praxis des Druckgusses. Fachverlag Schiele \& Schön GmbH, Berlin (2011)

12. Eigenfeld, K., Jäckel, E.: Gutachten zur Bauteilanalyse. TU Bergakademie Freiberg, Gießerei-Institut (2012)

13. Gerth, N., Fischer, A., Hamann, I., Sauer, H., Müller, B., Rädel, T., Gebauer, M., Toeppel, T.: Prozessoptimierung im Druckgießverfahren - Laserstrahlgeschmolzener Werkzeugeinsatz im Praxistest. Giesserei 100(4), 34-41 (2013)

14. Gerth, N., Sauer, H., Gebauer, M., Rädel, T.: Prozessoptimierung in der Fertigung einer Lagertraverse. MTZ Motortechnische Zeitschrift 74(06), 488-493 (2013) 